OPEN ACCESS

Edited by:

Marco De Curtis,

Fondazione IRCCS Istituto

Neurologico Carlo Besta, Italy

Reviewed by:

Sreekanth Puttachary,

Oregon State University, United States

Divya Vohora,

Jamia Hamdard University, India

${ }^{*}$ Correspondence:

Jianping Wu

biojpwu@ccmu.edu.cn

Qun Wang

wangq@ccmu.edu.cn

Specialty section:

This article was submitted to

Epilepsy,

a section of the journal

Frontiers in Neurology

Received: 25 December 2020

Accepted: 05 May 2021

Published: 28 May 2021

Citation:

Sun L, Shan W, Yang H, Liu R, Wu J and Wang Q (2021) The Role of Neuroinflammation in Post-traumatic Epilepsy. Front. Neurol. 12:646152. doi: 10.3389/fneur.2021.646152

\section{The Role of Neuroinflammation in Post-traumatic Epilepsy}

\author{
Lei Sun ${ }^{1,2,3}$, Wei Shan ${ }^{1,2,3}$, Huajun Yang ${ }^{2,4}$, Ru Liu ${ }^{1,2,3}$, Jianping $W^{1,2,3 *}$ and Qun Wang ${ }^{1,3,5 *}$ \\ ${ }^{1}$ Beijing Tiantan Hospital, Capital Medical University, Beijing, China, ${ }^{2}$ Advanced Innovation Center for Human Brain \\ Protection, Capital Medical University, Beijing, China, ${ }^{3}$ National Center for Clinical Medicine of Neurological Diseases, Beijing, \\ China, ${ }^{4}$ Beijing Friendship Hospital, Capital Medical University, Beijing, China, ${ }^{5}$ Beijing Institute for Brain Disorders, Beijing, \\ China
}

Post-traumatic epilepsy (PTE) is one of the consequences after traumatic brain injury (TBI), which increases the morbidity and mortality of survivors. About $20 \%$ of patients with TBI will develop PTE, and at least one-third of them are resistant to conventional antiepileptic drugs (AEDs). Therefore, it is of utmost importance to explore the mechanisms underlying PTE from a new perspective. More recently, neuroinflammation has been proposed to play a significant role in epileptogenesis. This review focuses particularly on glial cells activation, peripheral leukocytes infiltration, inflammatory cytokines release and chronic neuroinflammation occurrence post-TBI. Although the immune response to TBI appears to be primarily pro-epileptogenic, further research is needed to clarify the causal relationships. A better understanding of how neuroinflammation contributes to the development of PTE is of vital importance. Novel prevention and treatment strategies based on the neuroinflammatory mechanisms underlying epileptogenesis are evidently needed.

\section{SEARCH STRATEGY}

Search MeSH Terms in pubmed: "[“Epilepsy”(Mesh)] AND "Brain Injuries, Traumatic"[Mesh]". Published in last 30 years. 160 results were founded. Full text available:145 results. Record screened manually related to Neuroinflammation and Post-traumatic epilepsy. Then finally 123 records were included.

Keywords: post-traumatic epilepsy, traumatic brain injury, neuroinflammation, epileptogenesis, immunotherapy

\section{INTRODUCTION}

Epilepsy is a chronic neurological disease that is characterized by recurrent, transient and episodic discharge of neurons in the brain. The recurrent and frequent seizures seriously affect patients' life quality and cause a substantial economic burden to society and family (1). Post-traumatic seizure (PTS) is one of the severe consequences of brain trauma, with an incidence ranging from 4 to $53 \%(2,3)$. According to different latency from injury to seizure onset, PTS can be divided into immediate $(<24 \mathrm{~h})$, early $(1-7 \mathrm{~d})$, or late $(>1$ week) seizures, and only the recurrent late seizures can be called post-traumatic epilepsy (PTE) $(4,5)$. Therefore, PTE can be generally defined as unprovoked and recurrent seizures that occur more than 1 week after traumatic brain injury (TBI), accounting for as high as $20 \%$ of acquired epilepsy and $4 \%$ of all patients with epilepsy (6). Injury severity, age, and surgical methods after trauma are important risk factors for developing 
PTE. Moreover, we should also consider other factors such as hypoxia, hyperthermia, intracerebral bleeding, infection, or status epilepticus (SE) combining TBI that may increase PTE risk.

The pathogenesis of PTE is not yet clear. A growing body of evidence from clinical and experimental studies suggested the involvement of neuroinflammation in the process of epileptogenesis post TBI (7-9). Acute and early epileptic attacks may be a direct response to brain injury: Epidural and subdural hematoma, cerebral edema and brain contusion occur at the time of head impact can compress and stimulate the focal damaged tissue, which may cause blood-brain barrier (BBB) breakdown and reduce the threshold of seizure $(10,11)$. In contrast, the late onset is mediated by several factors including, but not limited to: generation of oxygen free radicals, abnormal release of excitotoxicity neurotransmitters, neuroimmune abnormalities caused by the inflammatory response, and neural network remodeling consisting of neurogenesis and neurodegeneration. The complexity of mechanisms and the severity of injury are the leading causes of the different outcomes and prognosis of PTE patients. Neuroinflammation is a crucial component of the epileptogenesis following TBI, and is also a promising target for treatment. Since neuroinflammatory mechanisms can be harmful or beneficial, it is necessary to have a good understanding of the timing and complexity of the immune response after TBI before developing immunomodulatory therapies to develop new preventative treatments of PTE.

\section{NEUROINFLAMMATION SECONDARY TO TBI DRIVING PTE}

TBI is one of the common emergencies in neurosurgery with high rates of mortality and disability. There is increasing evidence that TBI can cause direct and immediately impacts and evolves over time, contributing to long-term sequelae, such as behavioral disturbances, epilepsy and neurodegenerative disorders (12). The pathological mechanisms are characterized by a robust immune response, including BBB damage, activation of glial cells, infiltration of peripheral leukocytes, and release of pro- and anti-inflammatory cytokines (IL-1 $\beta$, HMGB1 TGF- $\beta$, TNF- $\alpha$, etc.). Over time, from months to years,

Abbreviations: AD, Alzheimer's disease; AEDs, Antiepileptic drugs; AMPA, $\alpha$-Amino-3-hydroxy-5-methyl-4-isoxazoleproprionic Acid; AQP4, Aquaporin-4; BBB, Blood-brain barrier; CNS, Central nervous system; CSF, Cerebrospinal fluid; CTE, Chronic traumatic encephalopathy; DAMPs and PAMPs, Damageor pathogen-associated molecule patterns; FPI, Fluid-percussion injury; FS, Febrile seizures; GFAP, Glial fibrillary acidic protein; GLT, Glutamate transporter; Glu, Glutamate; Gn, Glutamine; GS, Glutamine synthetase; ICE, IL-converting enzyme; IGF1, Insulin-like growth factor 1; IL-1, Interleukin-1; KA, Kainic acid; MAPK, Mitogen-activated protein kinase; MHC, Major histocompatibility complex; MMP9, Matrix metalloproteinase 9; mTBI, mild traumatic brain injury; NFTs, Neurofibrillary tangles; NF- $\kappa$, Nuclear factor kappa-B; NGF, Nerve growth factor; NLRs, Nucleotide-binding oligomerization domain like receptors; NMDA, N-methyl-D-aspartate; NO, Nitric oxide; PP2A, Protein phosphatase 2A; PRRs, Pattern recognition receptors; PTE, Post-traumatic epilepsy; PTS, Post-traumatic seizure; RAGE, Receptor for advanced glycation end products; ROS, Reactive oxygen species; SE, Status epilepticus; SNPs, Single nucleotide polymorphisms; TBI, Traumatic brain injury; TLE, Temporal lobe epilepsy; TLRs, Toll-like receptors. neurogenesis and neuroplasticity caused by injury help repair and regeneration, and an ongoing chronic neuroinflammation promotes neurodegeneration. These pathological processes lead to excessive excitation of neurons and ultimately drive PTE development (Figure 1).

The immune system is considered to react to injury with a two-phase response: innate immunity and adaptive immunity, the latter characterized by antigen-specificity and "remember" ability, which plays a vital role in our defense against pathogens. Innate immune response secondary to damaged or infected central nervous system (CNS) is mediated partly by damageor pathogen-associated molecule patterns (DAMPs and PAMPs) (13). By interacting with "danger" sensors-pattern recognition receptors (PRRs), such as toll-like receptors (TLRs), nucleotidebinding oligomerization domain (NOD) like receptors (NLRs), and scavenger receptors, pathogens and danger signals can act to initiate the innate immune response. Innate immune cells (e.g., phagocytes, granulocytes and T lymphocytes et al) can then release cytokines and chemokines that amplify the inflammatory cascade. Adaptive (or acquired) immunity is a more targeted response, which develop immunological memory to a specific pathogen in an initial response. CD8 and CD4 T lymphocytes recognize major histocompatibility complex (MHC) and play cytotoxic, helper or regulatory roles. On the other hand, B lymphocytes can produce immunoglobulins and participate in $\mathrm{T}$ cell activation (14).

Inflammasome, a multi-protein complex assembled by cytosolic receptors, is an essential component of the innate immune system and upon activation can be involved in the production of pro-inflammatory cytokines. NLRP1, NLRP3, NLRC4, and AIM2 are the most concerned inflammasomes in brain. Inflammasomes, especially NLRP3, can recognize DAMPs or PAMPs, recruit and activate pro-inflammatory protease Caspase-1. Activated Caspase-1 cleaves the precursors of IL$1 \beta$ and IL-18 into their mature forms, which plays a vital role in promoting sterile immune response following TBI (15, 16). In addition to inducing cytokine release, activation of inflammasomes can also mediate pyroptosis, a form of necrotic cell death (17). Adamczak et al. (18) found that inflammasome components caspase-1, ASC and NLRP-1 were significantly elevated in the cerebrospinal fluid (CSF) of patients with moderate or severe brain trauma, and the levels of these proteins were correlated with unfavorable outcomes. One study showed that administration of anti-ASC antibodies in a mouse of fluidpercussion injury (FPI) model reduced capase-1 activation and IL-1 $\beta$ generation, resulting in a decrease in brain lesion volume. These data indicate that inflammasome proteins might serve as potential biomarkers to assess inflammation and TBI severity.

\section{Microglial Activation}

Microglia are sentinel cells of the CNS and are often the first responders to brain damage. Under physiological conditions, microglia are resting, capable of sensing inflammatory signals, promoting neuronal survival and synaptic remodeling, thus playing an "immune surveillance" role. After TBI, microglial cells can be activated rapidly and sustained for several years in the brain (19). Microglia response to brain trauma has several 


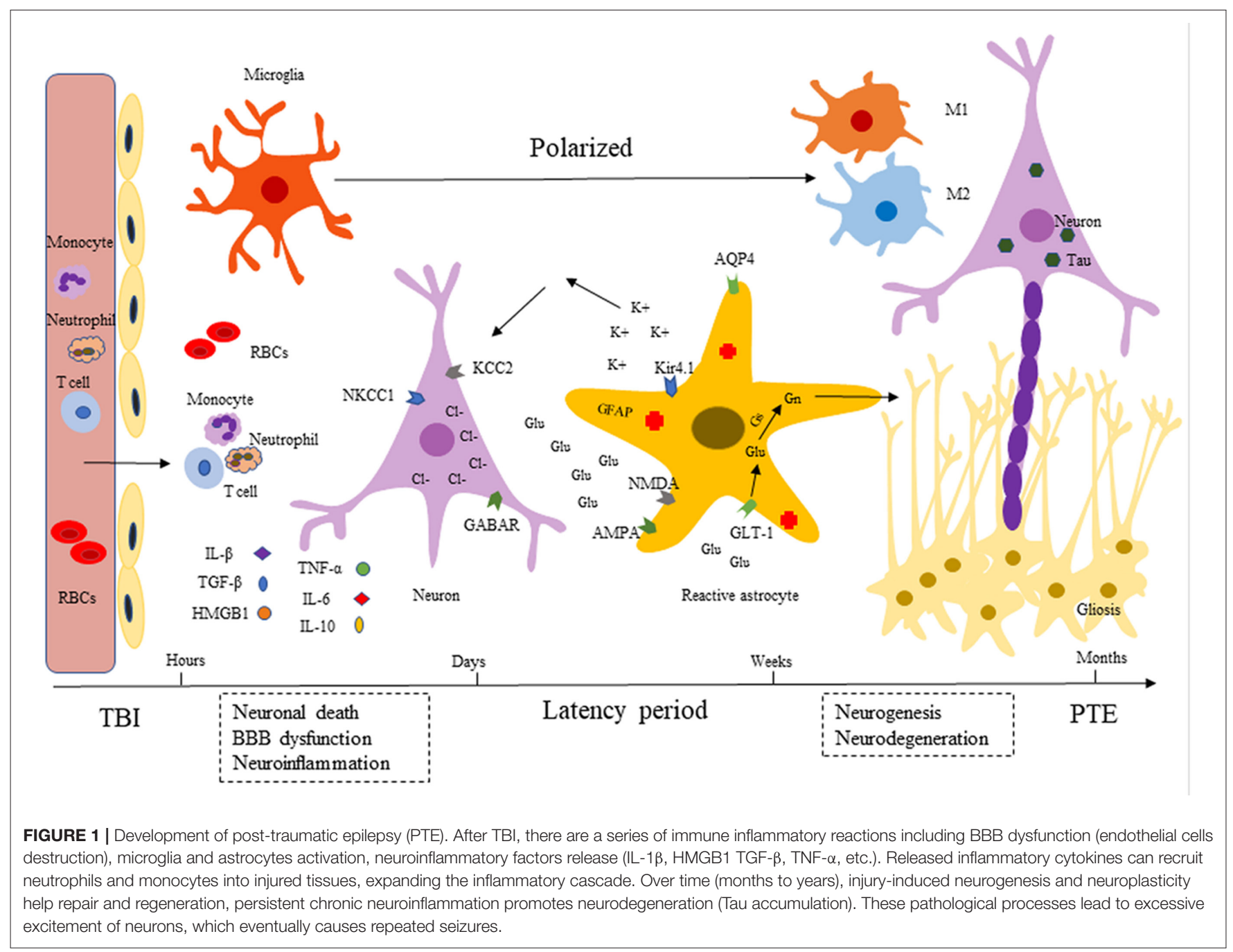

phases, including morphological transformation, proliferation, migration, phagocytosis and chemokines or cytokines release $(19,20)$. After acute classical activation, microglia can release various inflammatory mediators, including IL-1 $\beta$, IL-6, TNF$\alpha$, nitric oxide (NO), metalloproteinases, and reactive oxygen species (ROS). The production of these inflammatory mediators can promote the immune response to TBI by increasing BBB permeability and facilitating peripheral immune cell recruitment. The researchers found that minocycline specifically inhibited the activation of microglia and monocytes, which could reduce the volume of trauma foci and improve the neurological outcome of the mice (21). However, it is worth noting that microglia are highly plastic cells, and how they promote sterile immune response also rely on their activation state, type of damage, and interaction with neighboring cells, etc. Their effect on TBI should be considered in terms of time and context. In the same damaged brain tissue, microglia may be in different functional states, which are determined by the expression of molecules such as adhesion, maturation, effector, and among others. The conventional wisdom is that microglia, stimulated by injury, can be activated and polarized into two major phenotypes: M1-like (classical activation) and M2-like (alternative activation).

M1-like activated microglia can express IL-1, HMGB1, TNF- $\alpha$ and other cytokines that promote inflammatory reaction, which is involved in PTE occurrence. In contrast, inflammation mediators secreted by M2-like microglia can downregulate the responses of M1-like microglia, thus potentially inhibiting epileptogenesis. Microglial polarization may be a critical contributor that is directly associated with the pathological prognosis of epileptogenesis. Promoting and maintaining M2-like microglial phenotype after brain injury could be a potential preventive strategy for PTE. However, the current research on M1 and M2-like microglial polarization after TBI is still in the preliminary stage, and the correlation of the findings with epilepsy is even less known. Benson et al. (22) compared microglial polarization in two different acquired temporal lobe SE models, the results showed that pilocarpine-induced SE expressed both M1 and M2 markers, but only M1 markers were upregulated in kainate-induced SE model, which may explain why kainate-induced seizures attack more frequently. 
Therajaran et al. (23) summarized the possible epileptogenic mechanisms induced by microglial cell polarization, which mainly included altering excitation/inhibition balance, extracellular matrix, oxidative stress regulation, synaptic remodeling and neurodegeneration. In recent years, Hickman et al. (24) have used single-cell sequencing to analyze the gene expression of microglia in aging, and found that microglial polarization representing a mixed and complex state even in the normal physiological aging process. Therefore, oversimplifying microglia polarization into the M1/M2 phenotype does not reflect the microglia/macrophage functional polymorphism in the complex diseases. The occurrence of PTE is result from a combination of multiple factors, and the underlying mechanism remains to be further explored.

\section{Reactive Astrocytes}

Astrocytes are the most widely distributed type of cells in the mammalian brain, and they are not only playing a supporting and isolating role in the CNS, but also participate in pathophysiological processes such as synaptic transmission, neuroimmunity, maintenance of internal environment, and promotion of nerve tissue repair and regeneration (25). Astrocytes play an important role in controlling cerebral blood flow and prevent harmful substances from entering the brain by participating BBB formation with capillary endothelial cells and basal membrane through their terminal foot process. In TBI early stage, astrocytes exert neuroprotective effects by ingesting glutamate(Glu) through glutamate transporters (GLTs), inactivating oxygen free radicals, regulating $\mathrm{Na}+/ \mathrm{K}+$ balance, and secreting neurotransmitters (26). Within a period after TBI, astrocytes can be activated as reactive astrocytes, which are characterized by high expression of glial fibrillary acidic protein (GFAP), hypertrophy of cell bodies, and extension of primary processes, etc. Astrocytes participate in inflammation through the HMGB1-receptor for advanced glycation end products (RAGE) signaling pathway, thereby activating nuclear factor kappa-B (NF-кB) signaling transduction (27). Reactive astrocytes can also secrete matrix metalloproteinase 9 (MMP9), affecting the integrity of BBB after TBI (28). The glial scar formed by the reactive hyperplasia of glial cells after brain injury, restricts axonal regeneration and functional connections, thereby impeding nerve recovery. Studies have found that astrocytes interact with microglia and other immune cells to produce cytokines, such as insulin-like growth factor 1 (IGF1) and nerve growth factor (NGF), which promote the healing following TBI (29).

Epilepsy has long been thought to be a specific neuronal disease caused by changes within neurons, but novel evidence challenges us to consider that astrocytes also play a nonnegligible role in acquired epilepsy. However, the relationship between reactive astrocytes and PTE is unclear. High extracellular potassium and Glu levels after TBI may be the main reasons for seizures induced by altered homeostasis of astrocytes. The homeostasis of extracellular $\mathrm{K}+$ is crucial for regulating neuronal excitability. Kir4.1 is an inward rectifying potassium channel highly expressed in astrocytes of the CNS, buffering excessive spatial potassium load and maintaining the dynamic balance of
$\mathrm{K}+$ in the neuronal environment (30). Insufficient $\mathrm{K}+$ buffering and severe seizures were observed in mice with conditional Kir4.1 knockout $(31,32)$. Similarly, it has been found that TBI injury can lead to loss or down-regulation of Kir4.1 channel of astrocytes (33) and induce PTE (34). A series of studies showed aquaporin-4 (AQP4) and Kir4.1 are co-expressed in astroglial end feet, where Kir4.1 regulates the buffering on extracellular $\mathrm{K}+$ and AQP4 mediates water homeostasis. AQP4 and Kir4.1 co-regulate extracellular interstitial water and electrolyte balance and play a pivotal role in neuronal excitability. Studies have shown that if the number of AQP4 channels is reduced, the ability of Kir4.1 to clear extracellular $\mathrm{K}+$ will be weakened, and the excitability of neurons will be increased, thus triggering seizures (35). The AQP4 and Kir4.1 channels of astrocytes may be new potential targets for the treatment of epilepsy.

Altered neurotransmitter metabolism in astrocytes may also contribute to epileptogenesis. Under normal conditions, the GLTs (mainly GLT1) on astroglial membrane can quickly remove the excess Glu in extracellular space and reduce the excitatory toxicity. Excitotoxic Glu can be converted into non-toxic glutamine $(\mathrm{Gn})$ under the action of glutamine synthetase (GS) after Glu uptake into glial cells. Gn is a substrate for neuronal synthesis of Glu and GABA in neurons. Blocking GS can lead to GABA inhibitory postsynaptic potential. Brain injury results in increased concentrations of extracellular Glu, which can not only overstimulate glutamate receptors such as $\alpha$-Amino-3-hydroxy5-methyl-4-isoxazoleproprionic Acid (AMPA) and N-methyl-Daspartate (NMDA), but also affect the function of GLT-1 in astrocytes. Osteen et al. (36) demonstrated that the increased excitability of neurons that survived in injury was related to the long-term activation of NMDA subunit receptors, especially NR2B. Samuelsson et al. (37) discovered that the level of GLT1 was temporarily decreased in the epilepsy model induced by injecting ferrous chloride, which restricted the uptake of Glu and led to seizures. The results indicated that astrocytic Glu transporter may be one of epileptogenesis mechanism after trauma.

New research point to a direct effect of reactive astrocytes in regulating neuronal function by weakening the inhibition of GABA receptors (38). Two antagonistically acting neuronal chloride $\left(\mathrm{Cl}^{-}\right)$transporters NKCC1 and KCC2 establish the transmembrane gradient for $\mathrm{Cl}^{-}$, which serves as the premise for inhibitory effect of GABA receptors. NKCC1 transports $\mathrm{Cl}^{-}$into the neuron cell body across the membrane to maintain high intracellular $\mathrm{Cl}^{-}$, while KCC2 shunts $\mathrm{Cl}^{-}$out of the cell to lower intracellular $\mathrm{Cl}^{-}$ concentration. Wang et al. (39) pointed out that NKCC1 expression was up-regulated after TBI, which is responsible for the intracellular $\mathrm{Cl}^{-}$concentration, and gene knockout of NKCC1 or NKCC1 inhibitor bumethanide could reduce seizure frequency. However, a specific KCC2 agonist is not yet available for clinical practice. Besides, long-term chronic epileptic seizures cause astrocytic hyperplasia to participate in hippocampal sclerosis, which will affect the normal physiological regulatory function of brain and play a role promoting epileptogenesis. 


\section{Peripheral Immune Cells}

sThe inflammatory response after TBI is not restricted to the CNS. Peripheral cells, such as neutrophils and T lymphocytes, monocytes and macrophages, can infiltrate into the brain through the broken $\mathrm{BBB}$, further complicating the primary injury and local inflammatory response. After activation of CNS resident immune cells, neutrophils are among the first peripheral cellular responders to arrive in the injured brain with just a few hours (40). Neutrophils can permeate through BBB under the induction of cytokines (e.g., TNF- $\alpha$, IL-1 $\beta$ ), chemokines (e.g., CXCL1, 2, 3) and purines, releasing a series of proteases that destroy microvessels and subsequent aggravate BBB destruction. Activated neutrophils are also ROS producer, facilitating oxidative stress and thereby neurodegeneration secondary to TBI $(41,42)$. While the above data suggest that neutrophils are predominantly detrimental, it is worth noting that neutrophils can also play a beneficial role in promoting neurological recovery after injury. Future research is needed to determine how neutrophils influence wound-healing. Neutrophils have been shown to affect $\mathrm{T}$-cells, including regulatory $\mathrm{T}$ cells, $\mathrm{CD} 8+\mathrm{T}$ cells, and CD4+ $\mathrm{T}$ cells, contributing to adaptive immunity (43). In addition, recruitment of neutrophils after TBI is usually accompanied by the arrival of monocytes that turn into macrophages. Macrophages derived from monocytes often participate in the injury response together with yolk-sac derived resident myeloid cells such as microglia, contributing to tissue repairment and even regeneration. However, sustained activation of proinflammatory macrophages is considered to be deleterious, and may lead to progressive neurodegeneration and dysfunction. The mechanism of monocytes recruitment after TBI relies on the production of local chemokine CCL2. Targeting CCL2/CCR2 chemokine signaling pathway can decrease the number of monocytes, which can reduce lesion size and promote neurological recovery $(44,45)$. CCR2 + mononuclear macrophages infiltration has also been observed in the epileptic tissues (46). Pharmacological inhibition of CCL2 or CCR2 can suppress lipopolysaccharide-induced seizures (47), suggesting an association between monocyte accumulation and seizure susceptibility. As mentioned above, these peripheral immune responses are involved in neuroinflammation. They may promote epileptogenesis following TBI, but how they modulate vulnerability to seizures has not yet been explored.

\section{Inflammatory Cytokines}

More recently, increasing evidence has supported that neuroinflammation plays a causal role in seizure induction and propagation. TBI gives rise to inflammatory cytokines, mainly including IL- $1 \beta$, TGF- $\beta$, HMGB1, TNF- $\alpha$, IL-6, and IL-10, which may be the critical inflammatory mediators involved in PTS/PTE (Table 1). These cytokines can recruit neutrophils and monocytes to infiltrate into damaged tissue, expanding the inflammatory cascade reaction (48, 49). Three key signaling pathways that may mediate the relation between neuroinflammation and epileptogenesis: IL-1 $\beta / \mathrm{IL}-1 \mathrm{R}$ signaling pathway, HMGB1/TLR4 signaling pathway, and TGF- $\beta$ /albumin signaling pathway (Figure 2$)(7,50)$. These signaling pathways are expected to be more important targets to modulate post-traumatic epileptogenesis.

\section{IL-1 $\beta$}

Interleukin-1(IL-1) is one of the key mediators involved in both focal and diffuse TBI inflammatory response. The proinflammatory factor IL- $1 \beta$ is the most characteristic member of the IL-1 family and is elevated quickly in damaged brain tissue. IL- $1 \beta$ binding to IL-1R can activate the downstream NF- $\kappa$, p38 mitogen-activated protein kinase (MAPK), Src family kinases, etc. Through MyD88-dependent or non-dependent signaling pathways, IL-1 $\beta / \mathrm{IL}-1 \mathrm{R}$ initiates intracellular signal transduction in hippocampal neurons (51). Under physiological conditions, IL- $1 \beta$ is undetectable, which can be upregulated within minutes to hours post-TBI and this high level may last for several months (52). IL-1 $\beta$ is a crucial initiator of the immune inflammatory response, and can involve in leukocytes recruitment, other inflammatory factors and chemokines release $(53,54)$, glial cells activation, and BBB disruption (55). Frugier et al. (52) found that IL- $1 \beta$ mRNA and protein levels significantly increased in patients who died post-injury, IL-1 $\beta$ neutralizing antibody $(56,57)$, IL1R1 antagonist (58) or IL-1R1 gene defect (59) could alleviate TBI-induced glial activation, neutrophil infiltration, brain edema and cognitive dysfunction in animal models of TBI.

Elevated levels of IL-1 $\beta$ in CSF/serum/brain tissue are associated with the development of epilepsy (60). In a previous study, Diamond and his colleagues demonstrated that one of IL-1 $\beta$ functional single nucleotide polymorphisms (SNPs), "rs1143634," significantly raised PTE risks. In addition, elevated CSF/serum IL- $1 \beta$ ratio was also associated with increased PTE risks (50). In in vivo and in vitro experiments, IL- $1 \beta$ have been found to enhance the permeability and current strength of $\mathrm{Ca}^{2+}$, increase intracellular calcium $\left[\mathrm{Ca}^{2+}\right]_{\mathrm{I}}$ (61), downregulate of GABA (A) receptor function in hippocampal neurons (62) and inhibit the uptake of Glu by astrocytes (63) through AMPA and NMDA receptors. Consistent with these findings, Semple et al. (64) discovered that IL-1R antagonist could reduce seizure susceptibility 2 weeks after the mice injury, accompanied by reduced hyperplasia of hippocampal astrocytes, and spatial memory was improved 4 months later. Other members of the IL1 family such as IL- $1 \alpha$ have also been reported to up-regulate in brain tissue after TBI (65), but are not related to the prognosis of TBI or epilepsy. Taken together, these data support a key role for IL-1 $\beta$ in epileptogenesis, and implicate IL-1 $\beta /$ IL-1R signaling pathway as a potential target to prevent PTE.

\section{HMGB1}

TBI causes the release of DAMPs, such as HMGB1, ATP, heat shock proteins (HSPs), and S100. By interacting with PRRs, or RAGE, DAMPs act to activate intracellular signal transduction and initiate an inflammatory cascade. HMGB1 is a multifunctional protein whose function depends on its subcellular localization. In the nucleus, it plays the role of stabilizing nucleosomes, participating in gene transcription, and regulating DNA replication and repair. As a typical DAMPs, HMGB1 can be passively released by necrotic cells, or be actively secreted to the extracellular after tissue injury, activating the 
TABLE 1 | Key inflammatory cytokines involved in post-traumatic seizure/epilepsy.

\begin{tabular}{|c|c|c|c|c|c|}
\hline Factors & $\begin{array}{l}\text { Fluid/ } \\
\text { Tissue }\end{array}$ & Time course & Role in neuroinflammation & Signaling pathways & Role in epileptogenesis \\
\hline IL-1 $1 \beta$ & $\begin{array}{l}\text { CSF/ } \\
\text { ECF } \\
\text { Tissue }\end{array}$ & $\begin{array}{l}\text { Peak on day } 1-2 \text {, } \\
\text { decrease on day } \\
2-4 \text {. } \\
\text { Increased above } \\
\text { control 6-122 h } \\
\text { after injury. }\end{array}$ & $\begin{array}{l}\text { Pro-Inflammatory: } \\
\text { Mediates leukocytes recruitment, other } \\
\text { inflammatory factors and chemokines release, } \\
\text { glial cells activation, and BBB disruption. }\end{array}$ & 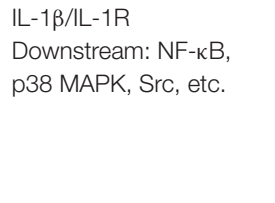 & $\begin{array}{l}\text { Pro-epileptogenesis: } \\
\text { Increases intracellular calcium [Ca2+]i; } \\
\text { Down-regulates GABA (A) receptor function; } \\
\text { Inhibits the uptake of Glu through AMPA and } \\
\text { NMDA receptors; } \\
\text { IL-1R antagonist reduces seizure susceptibility. }\end{array}$ \\
\hline TNF- $\alpha$ & $\begin{array}{l}\text { CSF/ } \\
\text { ECF } \\
\text { Tissue }\end{array}$ & $\begin{array}{l}\text { Peaks early on day } \\
1 . \\
\text { Increased above } \\
\text { control within } \\
17 \text { min of injury. }\end{array}$ & $\begin{array}{l}\text { Dual role: } \\
\text { Activates polymorphonuclear leukocytes; } \\
\text { releases ROS and various inflammatory } \\
\text { mediators; } \\
\text { Damages vascular endothelial cells, and } \\
\text { aggravates cerebral edema; } \\
\text { Inhibits NMDA-mediated calcium influx; } \\
\text { Promotes neurotrophin production. }\end{array}$ & $\begin{array}{l}\text { The TNF- } \alpha \text { signaling } \\
\text { pathway is mediated by } \\
\text { two membrane } \\
\text { receptors TNFR1(p55) } \\
\text { and TNFR2(p75) }\end{array}$ & $\begin{array}{l}\text { Dual role: } \\
\text { The p75 pathway is involved in the anti-seizure } \\
\text { activity of TNF- } \alpha \text {, whereas the pro-seizure } \\
\text { effect is mediated by the p55 pathway; } \\
\text { The role of TNF- } \alpha \text { signaling pathway in } \\
\text { epileptogenesis after TBI remains unclear. }\end{array}$ \\
\hline IL-6 & $\begin{array}{l}\text { CSF/ } \\
\text { ECF } \\
\text { Tissue }\end{array}$ & $\begin{array}{l}\text { Peak on day } 1 \text {, } \\
\text { decline on day } \\
2-3 \text {. } \\
\text { Increased above } \\
\text { control within } \\
17 \text { min of injury. }\end{array}$ & $\begin{array}{l}\text { Dual role: } \\
\text { Increases adhesion molecules and chemokines } \\
\text { secretion and enhances leukocyte recruitment; } \\
\text { Inhibits the production of TNF- } \alpha \text { and reduces } \\
\text { NMDA-mediated calcium influx. }\end{array}$ & - & $\begin{array}{l}\text { Dual role: } \\
\text { IL-6 can be upregulated after limbic status } \\
\text { epilepticus; } \\
\text { Over-expression of IL-6 results in seizure } \\
\text { threshold reduction; } \\
\text { Promotes hippocampal GABAergic neurons } \\
\text { loss, leading to an increased propensity for } \\
\text { seizures. }\end{array}$ \\
\hline
\end{tabular}

innate immune system. TLR4 is the hypothesized receptor of HMGB1 and mainly distributed in neurons and glial cells. Here, we particularly focus on HMGB1/TLR4 axis which recently are known to be implicated in TBI-induced immune inflammatory response and epileptogenesis.

Recent studies have indicated that HMGB1 can regulate longterm enhancement and long-term inhibition of the hippocampus after activation of TLR and RAGE (66) and play a role in synaptic transmission and plasticity of neurons, which may be relevant to epileptogenesis and cognitive dysfunction. Kainate and bicuculline-induced acute and chronic epileptic model showed that HMGB1 was highly expressed in neurons and glial cells at the injured sites of mice, and could be transferred from the nucleus to the cytoplasm and then secreted to the extracellular space, suggesting that it might be involved in the initiation of epilepsy (67). New studies have noted that the ATP-gated ionophilic P2X7 receptor promotes the release of IL-1 $\beta$ and HMGB1 from glial cells by mediating the activation of NALP3 inflammasome, thereby facilitating seizures (68). The direct evidence of HMGB1 involved in PTE was that intracerebral injection of HMGB1 in mice accelerated the acute epileptic activity induced by convulsive drugs and increased the frequency and severity of seizures. HMGB1/TLR4 antagonist or anti-HMGB1 monoclonal antibody significantly increased the epileptogenic threshold, decreased both seizure duration and frequency $(67,69)$. A study using primary cultured hippocampal neurons found that TLR4 


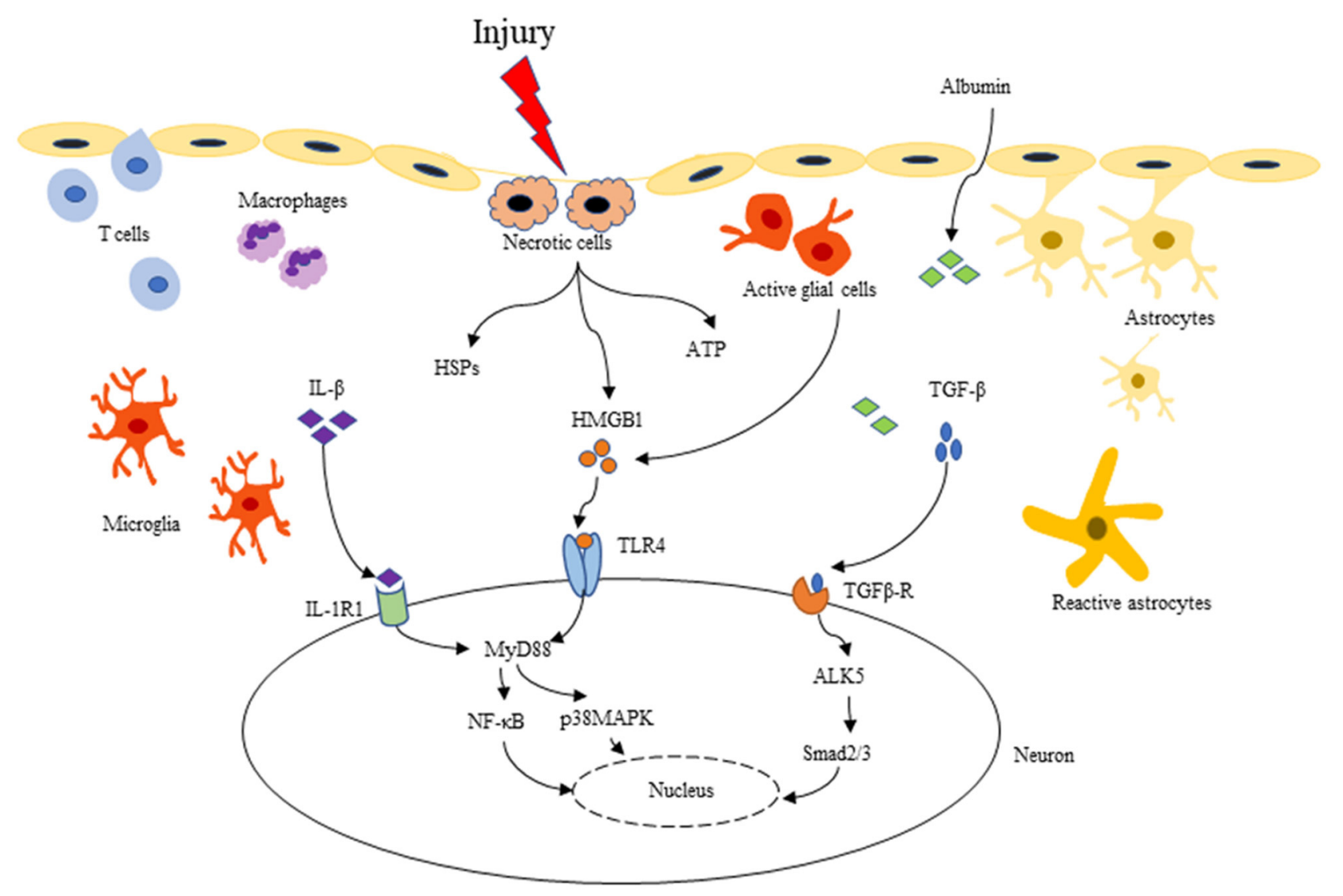

FIGURE 2 | Three key inflammatory signaling pathways related to PTE: IL-1 $\beta / I L-1 R, H M G B 1 / T L R 4$, and TGF- $\beta$ /albumin pathway. After TBI, BBB is destroyed, as well as microglia and astrocytes are activated. Pro-inflammatory cytokines such as IL-1 $\beta$, HMGB1 and TGF- $\beta$ are released into the extracellular matrix. IL-1 $\beta$ binding to $\mathrm{IL}-1 \mathrm{R}$ can activate the downstream NF-кB, p38 MAPK, Src, etc. and initiate intracellular signal transduction through MyD88-dependent or independent signaling pathways. HMGB1 can be passively released by necrotic cells, or be actively secreted to the extracellular from activated microglia and astrocytes, binding to many different types of cell receptors (TLR2/4, RAGE), and activating downstream signaling molecules like the IL-1B/IL-1R signaling pathway. In addition, TBI causes BBB destruction, serum albumin extravasates into the extracellular matrix, activating the TGF- $\beta$ /ALK5 pathway. These series of inflammatory cascades can lead to increased excitability and synaptic reconstruction, which in turn promotes the development of PTE.

mediated HMGB1 signaling phosphorylates NR2B subunit of NMDA receptor and promotes calcium influx, which is pivotal for inducing excitotoxicity and accelerating epileptogenesis (70). The HMGB1/TLR4 signaling pathway is similar to that of IL$1 \beta / \mathrm{IL}-1 \mathrm{R}$, which activates the downstream NF- $\mathrm{BB}$ and MAPK through the MyD88-dependent or independent pathways, and promotes the neurovascular dysfunction. Inhibiting TLR-4 can reduce brain edema and IL-6 production post-TBI (71). Overall, there is much accumulating evidence implicating HMGB1/TLR4 signaling pathway in epileptogenesis, however further studies are needed to prove their precise mechanism in PTE.

\section{TGF- $\beta$}

TGF- $\beta$ is a multifunctional cytokine involved in many different cellular processes such as cell proliferation, differentiation, adhesion, migration and apoptosis $(72,73)$. TGF- $\beta$ can be up-regulated in various CNS diseases, including multiple sclerosis, Alzheimer's disease (AD), stroke, and TBI. Clinical studies found that TGF- $\beta$ in CSF was significantly elevated
$24 \mathrm{~h}$ after TBI, and gradually recovered after 21 days, and the level of TGF- $\beta$ was related to the function of BBB (74). TGF- $\beta$ is mediated by two TGF- $\beta$ receptors (TGF $\beta$ R I and TGF $\beta$ R II), which phosphorylates downstream Smads protein (Smad $1 / 5$ or Smad 2/3) through ALK1 and ALK5 receptors, activates NF- $\mathrm{B}$ or $\mathrm{MAPK}$, and regulates target gene transcription.

Is TGF- $\beta$ associated with epileptogenesis? Animal experiments have shown that TGF- $\beta$ upregulation in neurons of amygdale-kindled rats (75) and in hippocampal astrocytes of SE models (76), supporting the potential role of TGF- $\beta$ in epileptogenesis. BBB dysfunction is a hallmark of brain injury. TGF- $\beta$ has also been demonstrated to be involved in microglial activation (77) and pericyte-induced BBB function (78). Increased BBB permeability was found in MRI of PTE patients, which was consistent with the site of epileptogenic foci (79). Studies on the ultrastructure of surgically resected epileptic tissues have confirmed significant anatomical abnormalities in $\mathrm{BBB}$ components, including endothelial cells, basement 
membranes, and tight junctions (80). van Vliet et al. (81) found a positive correlation between BBB permeability and seizure frequency in the chronic epileptic model, suggesting that BBB dysfunction is conducive to the development of temporal lobe epilepsy (TLE). In vivo and in vitro experiments (82) have confirmed that exosmic serum albumin post-injury could activate TGF- $\beta$ /ALK5 pathway of astrocytes, and TGF- $\beta$ inhibition, SJN2511, could effectively reduce and prevent synaptic remodeling and seizures. Consistent with this finding, Iven et al. (83) also found that TGF- $\beta 1$ was directly exposed to albumin after BBB destruction, which could cause local cortical dysfunction and induce epileptic discharge. One possible mechanism is local $\mathrm{BBB}$ damage leading to serum albumin seep into the cerebral cortex microenvironment. Albumin is uptake by astrocytes through its TGF $\beta$ R II, and then down-regulate membrane Kir4.1, resulting in an increase in extracellular potassium, which leads to excessive activation of NMDA receptors and causes neuronal hyperexcitability and epileptiform discharge. Antagonists, blocking albumin binding to TGF- $\beta$ receptors, have been reported to reduce or inhibit such epileptic activity (83). Transcriptome analysis revealed that TGF- $\beta 1$ induced a similar transcriptional regulation patterns when exposed to serum albumin; Blocking the TGF- $\beta$ signaling pathway not only reversed the transcriptional response after albumin exposure, but also prevented epileptic activity (84). Therefore, damage to microvessels during TBI may lead to serum albumin extravasation and inflammatory response, which are key steps in PTE development.

\section{TNF- $\alpha$}

TNF- $\alpha$, the primary subtype of TNF, is one of the critical mediators involved in immune response and neuroinflammation in the CNS, and is known to be released acutely after tissue injury in an active fashion by reactive glial cells, neurons and vascular endothelial cells. TNF- $\alpha$ can activate polymorphonuclear leukocytes, release ROS and various inflammatory mediators, play an important role in secondary brain injury. In addition, TNF- $\alpha$ can directly damage vascular endothelial cells, cause microvascular spasm, increase capillary permeability, and aggravate cerebral edema (85). The TNF- $\alpha$ signaling pathway is mediated by two membrane receptors TNFR1 (also called p55) and TNFR2 (also called p75). TNFR1, which is widely expressed, can be activated by binding to soluble TNF (solTNF) or transmembrane TNF (tmTNF) mediating downstream signaling pathways to initiate apoptosis (86). Compared with TNFR1, TNFR2 expression is limited and mainly released by microglia and endothelial cells known to regulate cell proliferation (87). Current studies have suggested that TNF- $\alpha$ may play a dual role as a pro-inflammatory and anti-inflammatory cytokine, depending on the timing and signaling cascade involved. Scherbel et al. (88) found in TNF- $\alpha$ knockout mice that TNF- $\alpha$ produced in the early stage of TBI may be deleterious, but the lack of TNF may increase neuronal loss and recovery time in the chronic period. TNF- $\alpha$ and IL-1 stimulate astrocytes to produce NGF and IL-10, which may be the basis of the neuroprotective and anti-inflammatory effects of TNF- $\alpha(89,90)$.
As for the demonstration of a dual role of TNF- $\alpha$ in neuroinflammation, studies have shown that TNF- $\alpha$ has both epileptogenic and antiepileptic effects. In one study, transgenic mice with neuronal overexpression of TNF- $\alpha$ developed seizures and early death (91). Another study demonstrated that mice lacking $\mathrm{TNF} \alpha$ receptors were observed to have prolonged seizures (92). The dichotomous role of TNF- $\alpha$ in seizures is thought to be mediated by the different receptors, p55 and p75. Balosso et al. suggested that the p75 pathway is involved in the anti-seizure activity of TNF- $\alpha$, whereas p55 pathway mediates the pro-seizure effect. However, the mechanism that determines the predominance of these two pathways has not yet been explored, the role of TNF- $\alpha$ signaling pathway in epileptogenesis after TBI remains unclear.

\section{IL-6}

IL-6 is a multifunctional factor that can be secreted by several cells in the CNS, including microglia, astrocytes and neurons, and may also play a dual role in neuroinflammation following TBI. IL- 6 has been reported to increase adhesion molecules and chemokines secretion, enhancing leukocyte recruitment and acting as a pro-inflammatory cytokine. In contrast, IL-6 can inhibit the production of TNF- $\alpha$, and reduce NMDA-mediated calcium influx. Swartz et al. (93) showed that IL-6-deficient mice were found to have a slowed healing process following TBI, whereas overexpression of IL- 6 resulted in a more rapid recovery by improving re-vascularization of the injury site.

Similarly, there is some evidence also implicated a role for IL-6 in seizure pathologies.

IL-6, IL-1 $\beta$, and TNF- $\alpha$ were rapidly upregulated $2 \mathrm{~h}$ after limbic SE induced by electrical stimulation, peaking at $6 \mathrm{~h}$, which may cause hyperexcitability in epileptic tissue (94). IL6 was also upregulated in the CSF of patients with newly diagnosed tonic-clonic seizures (95). Elevated IL-6 in the CSF or plasma has been reported to be associated with the severity of epileptic seizures. Transgenic mice over-expression of IL6 resulted in seizure threshold reduction and hippocampal excitation augment. In fact, IL-6 et al. inflammatory cytokines may promote hippocampal GABAergic neuron loss, leading to an increased propensity for seizures owing to reduced inhibitory interneurons (96).

\section{IL-10}

The cytokine IL-10 is a potent anti-inflammatory cytokine, which is found in the CSF of patients with TBI. Intravenous injection of IL-10 significantly reduced proinflammatory cytokine expression (particularly TNF- $\alpha$ and IL-1) and improved neurological outcome in lateral FPI model of rats (89). It has been indicated that IL-10 plays a neuroprotective role by acting on the peripheral immune system and is associated with circulating monocytes which can inhibit leukocyte recruitment and accumulation.

Although few studies have shown that IL-10 regulates susceptibility to seizures after TBI, several animal studies have indicated its anti-seizure effects. For example, IL-10 application was shown to eliminate the hypoxia-evoked epileptiform activity in rat hippocampal slices (97). Another study suggested that IL10 was genetically related to febrile seizures (FS) in rats, the 
seizure threshold temperature in IL-10 treated rats was higher than that in control groups, indicating that IL-10 made animals more resistant to FS (98). The antiepileptic functions of IL-10 are thought to be due to the anti-inflammatory effects of cytokines.

\section{Chronic Neuroinflammation}

About a quarter of TBI patients develop progressive neurodegenerative syndromes such as $\mathrm{AD}$, chronic traumatic encephalopathy (CTE), and PTE. The underlying pathogenesis remains unclear, but inflammation has received increased attention from researchers in recent years concerning the pathophysiologic mechanism of various neurodegenerative conditions. As we all know, the pathogenesis of $\mathrm{AD}$ is still controversial. There are several hypothetical mechanisms, such as $\mathrm{A} \beta$ cascade reaction, Tau hyperphosphorylation, cholinergic hypothesis, etc. However, several lines of evidence suggest that chronic neuroinflammation caused by brain trauma may be a potential factor for $\mathrm{AD}$. Studies in $\mathrm{AD}$ models have suggested that neuroinflammatory cytokines and reactive microglia can promote the accumulation and deposition of pathological tau, which may explain the relationship between TBI-induced inflammation and the predisposition to $\mathrm{AD}(99,100)$. But how $A \beta$ induces neuronal hyperexcitability is still unknown $(101,102)$. Ren et al. (103) explained the possible mechanism through whole-cell recordings of mouse brain slices. They found that $A \beta$ promotes dopamine release in the anterior cingulate cortex, overactivating D1 receptors on interneurons which inhibits GABA release, and then leading to excitatory/inhibitory imbalance. In addition, the accumulation of $A \beta$ has been shown to induce microglial activation and pro-inflammatory mediators release (104). The production of $A \beta$ toxicity after TBI and the disruption of neurotransmitters such as dopamine may have an impact in the development of PTE through inflammatory mechanisms, but this question remains to be further explored. CTE is a progressive neurodegenerative disease associated with repeated head injury, and is most common in athletes and soldiers (105). Studies have shown that activated microglia can last for several years after brain injury, suggesting that a role for a persistent TBI-induced neuroinflammation in CTE development (106). Aungst et al. (107) found that chronic inflammation caused by repeated mild traumatic brain injury (mTBI) can change hippocampal synaptic plasticity, leading to sustained cognitive and neuropsychiatric changes.

In the Kainic acid (KA)-induced acute epilepsy model, the hyperphosphorylated Tau was significantly increased, and the time and location of Tau were consistent with that of mossy fiber sprouting (108). Recent studies have demonstrated that late-onset seizures after TBI are also accompanied by a certain degree of neuronal degeneration and hyperphosphorylated tau (109). Neurofibrillary tangles (NFTs) consisted of Tau were also found in surgical specimens of patients with refractory epilepsy and focal cortical dysplasia, and these Tau tangles are specifically located in the dysplastic area $(110,111)$. Protein phosphatase 2A (PP2A) appears to be a major serine/threonine protein phosphatase that plays a negative regulatory role in signal transduction, and its increased activity can promote the dephosphorylation of hyperphosphorylated tau (112).
Studies (113) have reported that selenate specifically targets hyperphosphorylated tau, enhances PP2A activity and inhibits seizures in multiple epileptic animal models, suggesting that this may be a new approach to the treatment of PTE. Hippocampal sclerosis is associated with tau protein degeneration in patients with PTE (109). However, there is still no definitive proof showing the hyperphosphorylated tau-based mechanisms in PTE. A comprehensive understanding of the relationship between chronic neuroinflammation and PTE will require more research or more advanced neuroimaging techniques (such as PET imaging) that enable us to study the potential mechanisms of $A \beta$ deposition, tau phosphorylation and microglia/astrocytes activation in neurodegenerative diseases post-TBI.

\section{THERAPEUTIC TARGETS}

Although neuroinflammation is increasingly recognized as a critical mechanism in the development of epilepsy, few studies have been conducted on immune-targeted pharmaceuticals of PTE to date. A phase IIA clinical trial showed that the selective IL-converting enzyme (ICE)/Caspase 1 inhibitor VX765 could effectively alleviate seizures in some patients and continue for a period of time after drug discontinuation (114). Anakinra, an IL-1R1 antagonist, has also been demonstrated to reduce refractory epilepsy (115). The broad-spectrum antibiotic minocycline was reported to inhibit the microglial activation and proinflammatory factors release, reducing the frequency of seizures in patients with drug-resistant epilepsy (116). Given the complex, and variable inflammatory pathways associated with, combinations of anti-inflammatory drugs may be more effective than a single medication. VX-765 and TLR4 antagonist therapy on the IL-1R1/TLR-4 signaling pathway effectively prevented the epilepsy progression and significantly reduced the chronic seizures (117). Similarly, Kwon et al. (118) found in the pilocarpine-induced SE model that a combination of COX2 inhibitor CAY10404 and minocycline was more effective than single drug in reducing neuron damage of the hippocampus CA1 region and spontaneous seizures. As mentioned above, the TGF- $\beta$ /albumin signaling pathway has also generated interest as an immune-therapeutic target for PTE. Studies have reported that angiotensin II type 1 receptor antagonist losartan can effectively block the TGF- $\beta$ activation induced by albumin, delay the development of acquired epilepsy and reduce the severity of seizures (119). Inducible nitric oxide synthase (iNOS) is a key mediator of immune activation and inflammation, and its inhibitor, 1,400 W, has shown to inhibit epileptogenesis in rodent models of epilepsy (120-122). It is important to note that some of the drug-resistant epilepsy therapies, such as non-steroidal anti-inflammatory drugs, steroids, cannabinoid drugs, ketogenic diet and vagus nerve stimulation, have also been proved to have an anti-inflammatory effect, but there is still a notable lack of conclusive evidence to delineate these relationships $(123,124)$. Anti-epileptic therapeutics targeting immune inflammation has shown great potential in preventing and treating PTE, which is worthy of further research. 


\section{CONCLUSIONS}

PTE is a severe complication of TBI, which significantly affects the quality of life of patients. As PTE is drugresistant in at least one-third of patients, further research is needed to find novel therapeutic strategies for preventing the development of epilepsy after TBI. Clinical and experimental evidence has emphasized brain neuroinflammation as a key factor contributing to epileptogenesis. This review presents our current understanding of the immune inflammatory response to PTE, including microglial activation, reactive astrocytes proliferation, peripheral immune cells infiltration, inflammatory cytokines release, chronic neuroinflammation and potential therapeutic targets. However, the pathogenesis of PTE is very complex and has not yet been fully elucidated. There are still many unknown areas worth exploring further. One of the most essential areas warranting investigation is the possible inflammatory signaling pathways, especially the TGF$\beta /$ albumin signaling pathway. Another field of concern is the relationship between neurodegeneration and PTE. Inhibiting tau

\section{REFERENCES}

1. Global, regional, and national burden of epilepsy, 1990-2016: a systematic analysis for the Global Burden of Disease Study 2016. Lancet Neurol. (2019) 18:357-75. doi: 10.1016/s1474-4422(18)30454-X

2. Zhao $\mathrm{Y}$, Wu H, Wang $\mathrm{X}$, Li J, Zhang S. Clinical epidemiology of posttraumatic epilepsy in a group of Chinese patients. Seizure. (2012) 21:322-6. doi: 10.1016/j.seizure.2012.02.007

3. Frey LC. Epidemiology of posttraumatic epilepsy: a critical review. Epilepsia. (2003) 44:11-7. doi: 10.1046/j.1528-1157.44.s10.4.x

4. Qian C, Lopponen P, Tetri S, Huhtakangas J, Juvela S, Turtiainen HM, et al. Immediate, early and late seizures after primary intracerebral hemorrhage. Epilepsy Res. (2014) 108:732-9. doi: 10.1016/j.eplepsyres.2014.02.020

5. Lucke-Wold BP, Nguyen L, Turner RC, Logsdon AF, Chen YW, Smith KE, et al. Traumatic brain injury and epilepsy: underlying mechanisms leading to seizure. Seizure. (2015) 33:13-23. doi: 10.1016/j.seizure.2015.10.002

6. Agrawal A, Timothy J, Pandit L, Manju M. Post-traumatic epilepsy: an overview. Clin Neurol Neurosurg. (2006) 108:43339. doi: 10.1016/j.clineuro.2005.09.001

7. Webster KM, Sun M, Crack P, O'Brien TJ, Shultz SR, Semple BD. Inflammation in epileptogenesis after traumatic brain injury. J Neuroinflammation. (2017) 14:10. doi: 10.1186/s12974-016-0786-1

8. Klein P, Dingledine R, Aronica E, Bernard C. Commonalities in epileptogenic processes from different acute brain insults: do they translate? Epilepsia. (2018) 59:37-66. doi: 10.1111/epi.13965

9. Vezzani A, Balosso S, Ravizza T. Neuroinflammatory pathways as treatment targets and biomarkers in epilepsy. Nat Rev Neurol. (2019) 15:45972. doi: 10.1038/s41582-019-0217-x

10. Dixon KJ, Dixon KJ, Dixon KJ, Dixon KJ, Dixon KJ. Pathophysiology of traumatic brain injury. Phys Med Rehabil Clin N Am. (2017) 28:21525. doi: 10.1016/j.pmr.2016.12.001

11. Aguiar CC, Almeida AB, Araújo PV, de Abreu RN, Chaves EM, do Vale OC, et al. Oxidative stress and epilepsy: literature review. Oxid Med Cell Longev. (2012) 2012:795259. doi: 10.1155/2012/795259

12. Sharp DJ, Scott G, Leech R. Network dysfunction after traumatic brain injury. Nat Rev Neurol. (2014) 10:156-66. doi: 10.1038/nrneurol.2014.15

13. Bianchi ME. DAMPs, PAMPs and alarmins: all we need to know about danger. J Leukoc Biol. (2007) 81:1-5. doi: 10.1189/jlb.0306164

14. Warrington R, Watson W, Kim HL, Antonetti FR. An introduction to immunology and immunopathology. Allergy Asthma Clin Immunol. (2011) 7(Suppl. 1):S1. doi: 10.1186/1710-1492-7-S1-S1 phosphorylation by sodium selenite may be a new approach to the treatment of delayed seizures. A better understanding of how the inflammatory response promotes epileptogenesis after TBI is the key to immune-targeted therapy.

\section{AUTHOR CONTRIBUTIONS}

LS conducted literature review and wrote the initial draft of the manuscript. WS, HY, and RL made preliminary revision. JW and QW made critical revision. All authors contributed to manuscript revision and approved the submitted version.

\section{FUNDING}

This work was supported by grants from National Key R\&D Program of China (No. 2017YFC1307501), Beijing-TianjinHebei Cooperative Basic Research Program (No. H2018206435) and the National Natural Science Foundation of China (81870935) to JW.
15. Freeman LC, Ting JP. The pathogenic role of the inflammasome in neurodegenerative diseases. J Neurochem. (2016) 136(Suppl. 1):2938. doi: 10.1111/jnc.13217

16. Walsh JG, Muruve DA, Power C. Inflammasomes in the CNS. Nat Rev Neurosci. (2014) 15:84-97. doi: 10.1038/nr n3638

17. Bergsbaken T, Fink SL, Cookson BT. Pyroptosis: host cell death and inflammation. Nat Rev Microbiol. (2009) 7:99109. doi: $10.1038 /$ nrmicro2070

18. Adamczak S, Dale G, de Rivero Vaccari JP, Bullock MR, Dietrich WD, Keane RW. Inflammasome proteins in cerebrospinal fluid of brain-injured patients as biomarkers of functional outcome: clinical article. J Neurosurg. (2012) 117:1119-25. doi: 10.3171/2012.9.jns12815

19. Ramlackhansingh AF, Brooks DJ, Greenwood RJ, Bose SK, Turkheimer FE, Kinnunen KM, et al. Inflammation after trauma: microglial activation and traumatic brain injury. Ann Neurol. (2011) 70:374-83. doi: 10.1002/ana.22455

20. Chhor V, Moretti R, Le Charpentier T, Sigaut S, Lebon S, Schwendimann L, et al. Role of microglia in a mouse model of paediatric traumatic brain injury. Brain Behav Immun. (2017) 63:197-209. doi: 10.1016/j.bbi.2016.11.001

21. Homsi S, Piaggio T, Croci N, Noble F, Plotkine M, Marchand-Leroux C, et al. Blockade of acute microglial activation by minocycline promotes neuroprotection and reduces locomotor hyperactivity after closed head injury in mice: a twelve-week follow-up study. J Neurotrauma. (2010) 27:911-21. doi: 10.1089/neu.2009.1223

22. Benson MJ, Manzanero S, Borges K. Complex alterations in microglial M1/M2 markers during the development of epilepsy in two mouse models. Epilepsia. (2015) 56:895-905. doi: 10.1111/epi.12960

23. Therajaran P, Hamilton JA, O’Brien TJ, Jones NC. Microglial polarization in posttraumatic epilepsy: potential mechanism and treatment opportunity. Epilepsia. (2020) 61:203-15. doi: 10.1111/epi.16424

24. Hickman SE, Kingery ND, Ohsumi TK, Borowsky ML, Wang LC, Means TK, et al. The microglial sensome revealed by direct RNA sequencing. Nat Neurosci. (2013) 16:1896-905. doi: 10.1038/nn.3554

25. Sofroniew MV, Vinters HV. Astrocytes: biology and pathology. Acta Neuropathol. (2010) 119:7-35. doi: 10.1007/s00401-009-0619-8

26. Burda JE, Bernstein AM, Sofroniew MV. Astrocyte roles in traumatic brain injury. Exp Neurol. (2016) 275(Pt 3):30515. doi: 10.1016/j.expneurol.2015.03.020

27. Gao TL, Yuan XT, Yang D, Dai HL, Wang WJ, Peng X, et al. Expression of HMGB1 and RAGE in rat and human brains after 
traumatic brain injury. J Trauma Acute Care Surg. (2012) 72:6439. doi: 10.1097/TA.0b013e31823c54a6

28. Pan H, Wang H, Wang X, Zhu L, Mao L. The absence of Nrf2 enhances NF-kappaB-dependent inflammation following scratch injury in mouse primary cultured astrocytes. Mediators Inflamm. (2012) 2012:217580. doi: 10.1155/2012/217580

29. Burda JE, Sofroniew MV. Reactive gliosis and the multicellular response to CNS damage and disease. Neuron. (2014) 81:22948. doi: 10.1016/j.neuron.2013.12.034

30. Olsen ML, Khakh BS, Skatchkov SN. New insights on astrocyte ion channels: critical for homeostasis and neuron-glia signaling. J Neurosci. (2015) 35:13827-35. doi: 10.1523/JNEUROSCI.2603-15.2015

31. Chever O, Djukic B, McCarthy KD, Amzica F. Implication of Kir4.1 channel in excess potassium clearance: an in vivo study on anesthetized glial-conditional Kir4.1 knock-out mice. J Neurosci. (2010) 30:1576977. doi: 10.1523/JNEUROSCI.2078-10.2010

32. Haj-Yasein NN, Jensen V, Vindedal GF, Gundersen GA, Klungland A, Ottersen OP, et al. Evidence that compromised $\mathrm{K}+$ spatial buffering contributes to the epileptogenic effect of mutations in the human Kir4.1 gene (KCNJ10). Glia. (2011) 59:1635-42. doi: 10.1002/glia.21205

33. D'Ambrosio R, Maris DO, Grady MS, Winn HR, Janigro D. Impaired $\mathrm{K}(+)$ homeostasis and altered electrophysiological properties of post-traumatic hippocampal glia. J Neurosci. (1999) 19:8152-62. doi: 10.1523/JNEUROSCI.19-18-08152.1999

34. Braganza O, Bedner $\mathrm{P}$, Huttmann $\mathrm{K}$, von Staden E, Friedman A, Seifert G, et al. Albumin is taken up by hippocampal NG2 cells and astrocytes and decreases gap junction coupling. Epilepsia. (2012) 53:1898906. doi: 10.1111/j.1528-1167.2012.03665.x

35. Amiry-Moghaddam M, Williamson A, Palomba M, Eid T, de Lanerolle NC, Nagelhus EA, et al. Delayed K+ clearance associated with aquaporin-4 mislocalization: phenotypic defects in brains of alpha-syntrophin-null mice. Proc Natl Acad Sci USA. (2003) 100:13615-20. doi: 10.1073/pnas.2336064100

36. Osteen CL, Giza CC, Hovda DA. Injury-induced alterations in Nmethyl-D-aspartate receptor subunit composition contribute to prolonged 45 calcium accumulation following lateral fluid percussion. Neuroscience. (2004) 128:305-22. doi: 10.1016/j.neuroscience.2004.06.034

37. Samuelsson C, Kumlien E, Flink R, Lindholm D, Ronne-Engstrom E. Decreased cortical levels of astrocytic glutamate transport protein GLT-1 in a rat model of posttraumatic epilepsy. Neurosci Lett. (2000) 289:1858. doi: 10.1016/S0304-3940(00)01284-2

38. Robel S, Sontheimer H. Glia as drivers of abnormal neuronal activity. Nat Neurosci. (2016) 19:28-33. doi: 10.1038/nn.4184

39. Wang F, Wang X, Shapiro LA, Cotrina ML, Liu W, Wang EW, et al. NKCC1 up-regulation contributes to early post-traumatic seizures and increased post-traumatic seizure susceptibility. Brain Struct Funct. (2017) 222:154356. doi: 10.1007/s00429-016-1292-z

40. Soares HD, Hicks RR, Smith D, McIntosh TK. Inflammatory leukocytic recruitment and diffuse neuronal degeneration are separate pathological processes resulting from traumatic brain injury. J Neurosci. (1995) 15:822333. doi: 10.1523/JNEUROSCI.15-12-08223.1995

41. Corps KN, Roth TL, McGavern DB. Inflammation and neuroprotection in traumatic brain injury. JAMA Neurol. (2015) 72:355-62. doi: 10.1001/jamaneurol.2014.3558

42. Dinkel K, Dhabhar FS, Sapolsky RM. Neurotoxic effects of polymorphonuclear granulocytes on hippocampal primary cultures. Proc Natl Acad Sci USA. (2004) 101:331-6. doi: 10.1073/pnas.0303510101

43. Mantovani A, Cassatella MA, Costantini C, Jaillon S. Neutrophils in the activation and regulation of innate and adaptive immunity. Nat Rev Immunol. (2011) 11:519-31. doi: 10.1038/nri3024

44. Semple BD, Bye N, Rancan M, Ziebell JM, Morganti-Kossmann MC. Role of CCL2 (MCP-1) in traumatic brain injury (TBI): evidence from severe TBI patients and CCL2-/- mice. J Cereb Blood Flow Metab. (2010) 30:76982. doi: $10.1038 / \mathrm{jcbfm} .2009 .262$

45. Gyoneva S, Kim D, Katsumoto A, Kokiko-Cochran ON, Lamb BT, Ransohoff RM. Ccr2 deletion dissociates cavity size and tau pathology after mild traumatic brain injury. $J$ Neuroinflammation. (2015) 12:228. doi: 10.1186/s12974-015-0 443-0
46. Zattoni M, Mura ML, Deprez F, Schwendener RA, Engelhardt B, Frei K, et al. Brain infiltration of leukocytes contributes to the pathophysiology of temporal lobe epilepsy. J Neurosci. (2011) 31:403750. doi: 10.1523/JNEUROSCI.6210-10.2011

47. Cerri C, Genovesi S, Allegra M, Pistillo F, Püntener U, Guglielmotti A, et al. The chemokine CCL2 mediates the seizureenhancing effects of systemic inflammation. J Neurosci. (2016) 36:3777-88. doi: 10.1523/JNEUROSCI.0451-15.2016

48. DeKosky ST, Blennow K, Ikonomovic MD, Gandy S. Acute and chronic traumatic encephalopathies: pathogenesis and biomarkers. Nat Rev Neurol. (2013) 9:192-200. doi: 10.1038/nrneurol.2013.36

49. Morganti-Kossmann MC, Rancan M, Stahel PF, Kossmann T. Inflammatory response in acute traumatic brain injury: a double-edged sword. Curr Opin Crit Care. (2002) 8:101-5. doi: 10.1097/00075198-200204000-00002

50. Diamond ML, Ritter AC, Failla MD, Boles JA, Conley YP, Kochanek PM, et al. IL-1beta associations with posttraumatic epilepsy development: a genetics and biomarker cohort study. Epilepsia. (2015) 56:9911001. doi: $10.1111 /$ epi.13100

51. Srinivasan D, Yen JH, Joseph DJ, Friedman W. Cell type-specific interleukin-1beta signaling in the CNS. J Neurosci. (2004) 24:64828. doi: 10.1523/JNEUROSCI.5712-03.2004

52. Frugier T, Morganti-Kossmann MC, O'Reilly D, McLean CA. In situ detection of inflammatory mediators in post mortem human brain tissue after traumatic injury. J Neurotrauma. (2010) 27:497-507. doi: 10.1089/neu.2009.1120

53. Woodcock T, Morganti-Kossmann MC. The role of markers of inflammation in traumatic brain injury. Front Neurol. (2013) 4:18. doi: $10.3389 /$ fneur.2013.00018

54. Aloisi F, Care A, Borsellino G, Gallo P, Rosa S, Bassani A, et al. Production of hemolymphopoietic cytokines (IL-6, IL-8, colony-stimulating factors) by normal human astrocytes in response to IL-1 beta and tumor necrosis factor-alpha. J Immunol. (1992) 149:2358-66.

55. Holmin S, Mathiesen T. Intracerebral administration of interleukinlbeta and induction of inflammation, apoptosis, and vasogenic edema. $J$ Neurosurg. (2000) 92:108-20. doi: 10.3171/jns.2000.92.1.0108

56. Clausen F, Hanell A, Bjork M, Hillered L, Mir AK, Gram H, et al. Neutralization of interleukin-1beta modifies the inflammatory response and improves histological and cognitive outcome following traumatic brain injury in mice. Eur J Neurosci. (2009) 30:385-96. doi: 10.1111/j.1460-9568.2009.06820.x

57. Clausen F, Hanell A, Israelsson C, Hedin J, Ebendal T, Mir $A K$, et al. Neutralization of interleukin-lbeta reduces cerebral edema and tissue loss and improves late cognitive outcome following traumatic brain injury in mice. Eur J Neurosci. (2011) 34:110-23. doi: 10.1111/j.1460-9568.2011.07723.x

58. Sanderson KL, Raghupathi R, Saatman KE, Martin D, Miller G, McIntosh TK. Interleukin-1 receptor antagonist attenuates regional neuronal cell death and cognitive dysfunction after experimental brain injury. J Cereb Blood Flow Metab. (1999) 19:1118-25. doi: 10.1097/00004647-199910000-00008

59. Lazovic J, Basu A, Lin HW, Rothstein RP, Krady JK, Smith MB, et al. Neuroinflammation and both cytotoxic and vasogenic edema are reduced in interleukin-1 type 1 receptor-deficient mice conferring neuroprotection. Stroke. (2005) 36:2226-31. doi: 10.1161/01.STR.0000182255.08 $162.6 \mathrm{a}$

60. de Vries EE, van den Munckhof B, Braun KP, van Royen-Kerkhof A, de Jager W, Jansen FE. Inflammatory mediators in human epilepsy: a systematic review and meta-analysis. Neurosci Biobehav Rev. (2016) 63:17790. doi: 10.1016/j.neubiorev.2016.02.007

61. Zhu G, Okada M, Yoshida S, Mori F, Ueno S, Wakabayashi K, et al. Effects of interleukin-1beta on hippocampal glutamate and GABA releases associated with Ca2+-induced Ca2+ releasing systems. Epilepsy Res. (2006) 71:107-16. doi: 10.1016/j.eplepsyres.2006.05.017

62. Wang $S$, Cheng Q, Malik S, Yang J. Interleukin-1beta inhibits gammaaminobutyric acid type A $(\mathrm{GABA}(\mathrm{A}))$ receptor current in cultured hippocampal neurons. J Pharmacol Exp Ther. (2000) 292:497-504.

63. Hu S, Sheng WS, Ehrlich LC, Peterson PK, Chao CC. Cytokine effects on glutamate uptake by human astrocytes. Neuroimmunomodulation. (2000) 7:153-9. doi: $10.1159 / 000026433$ 
64. Semple BD, O’Brien TJ, Gimlin K, Wright DK, Kim SE, CasillasEspinosa PM, et al. Interleukin-1 Receptor in Seizure Susceptibility after Traumatic Injury to the Pediatric Brain. J Neurosci. (2017) 37:786477. doi: 10.1523/JNEUROSCI.0982-17.2017

65. Lu KT, Wang YW, Yang JT, Yang YL, Chen HI. Effect of interleukin1 on traumatic brain injury-induced damage to hippocampal neurons. $J$ Neurotrauma. (2005) 22:885-95. doi: 10.1089/neu.2005.22.885

66. Costello DA, Watson MB, Cowley TR, Murphy N, Murphy Royal C, Garlanda C, et al. Interleukin-1alpha and HMGB1 mediate hippocampal dysfunction in SIGIRR-deficient mice. J Neurosci. (2011) 31:38719. doi: 10.1523/JNEUROSCI.6676-10.2011

67. Maroso M, Balosso S, Ravizza T, Liu J, Aronica E, Iyer AM, et al. Toll-like receptor 4 and high-mobility group box-1 are involved in ictogenesis and can be targeted to reduce seizures. Nat Med. (2010) 16:4139. doi: 10.1038/nm.2127

68. Engel T, Alves M, Sheedy C, Henshall DC. ATPergic signalling during seizures and epilepsy. Neuropharmacology. (2016) 104:140-53. doi: 10.1016/j.neuropharm.2015.11.001

69. Zhao J, Wang Y, Xu C, Liu K, Wang Y, Chen L, et al. Therapeutic potential of an anti-high mobility group box-1 monoclonal antibody in epilepsy. Brain Behav Immun. (2017) 64:308-19. doi: 10.1016/j.bbi.2017.02.002

70. Balosso S, Liu J, Bianchi ME, Vezzani A. Disulfide-containing high mobility group box-1 promotes $\mathrm{N}$-methyl-D-aspartate receptor function and excitotoxicity by activating Toll-like receptor 4-dependent signaling in hippocampal neurons. Antioxid Redox Signal. (2014) 21:1726-40. doi: 10.1089/ars.2013.5349

71. Laird MD, Shields JS, Sukumari-Ramesh S, Kimbler DE, Fessler RD, Shakir B, et al. High mobility group box protein-1 promotes cerebral edema after traumatic brain injury via activation of toll-like receptor 4. Glia. (2014) 62:26-38. doi: 10.1002/glia.22581

72. Blobe GC, Schiemann WP, Lodish HF. Role of transforming growth factor beta in human disease. $N$ Engl J Med. (2000) 342:1350-8. doi: 10.1056/NEJM200005043421807

73. Shi Y, Massague J. Mechanisms of TGF-beta signaling from cell membrane to the nucleus. Cell. (2003) 113:685-700. doi: 10.1016/S0092-8674(03)00432-X

74. Morganti-Kossmann MC, Hans VH, Lenzlinger PM, Dubs R, Ludwig E, Trentz O, et al. TGF-beta is elevated in the CSF of patients with severe traumatic brain injuries and parallels blood-brain barrier function. $J$ Neurotrauma. (1999) 16:617-28. doi: 10.1089/neu.1999.16.617

75. Plata-Salaman CR, Ilyin SE, Turrin NP, Gayle D, Flynn MC, Romanovitch AE, et al. Kindling modulates the IL-1beta system, TNF-alpha, TGF-betal, and neuropeptide mRNAs in specific brain regions. Brain Res Mol Brain Res. (2000) 75:248-58. doi: 10.1016/S0169-328X(99)00306-X

76. Aronica E, van Vliet EA, Mayboroda OA, Troost D, da Silva FH, Gorter JA. Upregulation of metabotropic glutamate receptor subtype mGluR3 and mGluR5 in reactive astrocytes in a rat model of mesial temporal lobe epilepsy. Eur J Neurosci. (2000) 12:2333-44. doi: 10.1046/j.1460-9568.2000.00131.x

77. Schilling T, Eder C. Effects of kinase inhibitors on TGF-beta induced upregulation of Kv1.3 K+ channels in brain macrophages. Pflugers Arch. (2003) 447:312-5. doi: 10.1007/s00424-003-1155-3

78. Dohgu S, Takata F, Yamauchi A, Nakagawa S, Egawa T, Naito M, et al. Brain pericytes contribute to the induction and up-regulation of bloodbrain barrier functions through transforming growth factor-beta production. Brain Res. (2005) 1038:208-15. doi: 10.1016/j.brainres.2005.01.027

79. Tomkins O, Shelef I, Kaizerman I, Eliushin A, Afawi Z, Misk A, et al. Bloodbrain barrier disruption in post-traumatic epilepsy. J Neurol Neurosurg Psychiatry. (2008) 79:774-7. doi: 10.1136/jnnp.2007.126425

80. Cornford EM. Epilepsy and the blood brain barrier: endothelial cell responses to seizures. Adv Neurol. (1999) 79:845-62.

81. van Vliet EA, da Costa Araujo S, Redeker S, van Schaik R, Aronica E, Gorter JA. Blood-brain barrier leakage may lead to progression of temporal lobe epilepsy. Brain. (2007) 130(Pt 2):521-34. doi: 10.1093/brain/awl318

82. Weissberg I, Wood L, Kamintsky L, Vazquez O, Milikovsky DZ, Alexander A, et al. Albumin induces excitatory synaptogenesis through astrocytic TGF-beta/ALK5 signaling in a model of acquired epilepsy following blood-brain barrier dysfunction. Neurobiol Dis. (2015) 78:11525. doi: 10.1016/j.nbd.2015.02.029
83. Ivens S, Kaufer D, Flores LP, Bechmann I, Zumsteg D, Tomkins O, et al. TGF-beta receptor-mediated albumin uptake into astrocytes is involved in neocortical epileptogenesis. Brain. (2007) 130(Pt 2):53547. doi: 10.1093/brain/awl317

84. Cacheaux LP, Ivens S, David Y, Lakhter AJ, Bar-Klein G, Shapira M, et al. Transcriptome profiling reveals TGF-beta signaling involvement in epileptogenesis. J Neurosci. (2009) 29:8927-35. doi: 10.1523/JNEUROSCI.0430-09.2009

85. Kim KS, Wass CA, Cross AS, Opal SM. Modulation of blood-brain barrier permeability by tumor necrosis factor and antibody to tumor necrosis factor in the rat. Lymphokine Cytokine Res. (1992) 11:293-8.

86. Konefal SC, Stellwagen D. Tumour necrosis factor-mediated homeostatic synaptic plasticity in behavioural models: testing a role in maternal immune activation. (2017) 372:1715-15. doi: 10.1098/rstb.2016.0160

87. McCoy MK, Tansey MG. TNF signaling inhibition in the CNS: implications for normal brain function and neurodegenerative disease. J Neuroinflammation. (2008) 5:45. doi: 10.1186/1742-2094-5-45

88. Scherbel U, Raghupathi R, Nakamura M, Saatman KE, Trojanowski JQ, Neugebauer E, et al. Differential acute and chronic responses of tumor necrosis factor-deficient mice to experimental brain injury. Proc Natl Acad Sci USA. (1999) 96:8721-6. doi: 10.1073/pnas.96.15.8721

89. Knoblach SM, Faden AI. Interleukin-10 improves outcome and alters proinflammatory cytokine expression after experimental traumatic brain injury. Exp Neurol. (1998) 153:143-51. doi: 10.1006/exnr.1998.6877

90. Balasingam V, Yong VW. Attenuation of astroglial reactivity by interleukin-10. J Neurosci. (1996) 16:294555. doi: 10.1523/JNEUROSCI.16-09-02945.1996

91. Probert L, Akassoglou K, Pasparakis M, Kontogeorgos G, Kollias G. Spontaneous inflammatory demyelinating disease in transgenic mice showing central nervous system-specific expression of tumor necrosis factor alpha. Proc Natl Acad Sci USA. (1995) 92:11294-8. doi: 10.1073/pnas.92.24.11294

92. Balosso S, Ravizza T, Perego C, Peschon J, Campbell IL, De Simoni MG, et al. Tumor necrosis factor-alpha inhibits seizures in mice via p75 receptors. Ann Neurol. (2005) 57:804-12. doi: 10.1002/ana.20480

93. Swartz KR, Liu F, Sewell D, Schochet T, Campbell I, Sandor M, et al. Interleukin-6 promotes post-traumatic healing in the central nervous system. Brain Res. (2001) 896:86-95. doi: 10.1016/S0006-8993(01)02013-3

94. De Simoni MG, Perego C, Ravizza T, Moneta D, Conti M, Marchesi F, et al. Inflammatory cytokines and related genes are induced in the rat hippocampus by limbic status epilepticus. Eur J Neurosci. (2000) 12:262333. doi: 10.1046/j.1460-9568.2000.00140.x

95. Peltola J, Palmio J, Korhonen L, Suhonen J, Miettinen A, Hurme M, et al. Interleukin-6 and interleukin-1 receptor antagonist in cerebrospinal fluid from patients with recent tonic-clonic seizures. Epilepsy Res. (2000) 41:20511. doi: 10.1016/S0920-1211(00)00140-6

96. Samland H, Huitron-Resendiz S, Masliah E, Criado J, Henriksen SJ, Campbell IL. Profound increase in sensitivity to glutamatergic- but not cholinergic agonist-induced seizures in transgenic mice with astrocyte production of IL-6. J Neurosci Res. (2003) 73:176-87. doi: 10.1002/jnr.10635

97. Levin SG, Godukhin OV. Protective effects of interleukin-10 on the development of epileptiform activity evoked by transient episodes of hypoxia in rat hippocampal slices. Neurosci Behav Physiol. (2007) 37:46770. doi: 10.1007/s11055-007-0036-1

98. Ishizaki Y, Kira R, Fukuda M, Torisu H, Sakai Y, Sanefuji M, et al. Interleukin-10 is associated with resistance to febrile seizures: genetic association and experimental animal studies. Epilepsia. (2009) 50:7617. doi: 10.1111/j.1528-1167.2008.01861.x

99. Maphis N, Xu G, Kokiko-Cochran ON, Jiang S, Cardona A, Ransohoff $\mathrm{RM}$, et al. Reactive microglia drive tau pathology and contribute to the spreading of pathological tau in the brain. Brain. (2015) 138(Pt 6):173855. doi: 10.1093/brain/awv081

100. Ghosh S, Wu MD, Shaftel SS, Kyrkanides S, LaFerla FM, Olschowka JA, et al. Sustained interleukin-1beta overexpression exacerbates tau pathology despite reduced amyloid burden in an Alzheimer's mouse model. J Neurosci. (2013) 33:5053-64. doi: 10.1523/JNEUROSCI.4361-12. 2013 
101. Costa C, Parnetti L, D’Amelio M, Tozzi A, Tantucci M, Romigi $A$, et al. Epilepsy, amyloid- $\beta$, and D1 dopamine receptors: a possible pathogenetic link? Neurobiol Aging. (2016) 48:16171. doi: 10.1016/j.neurobiolaging.2016.08.025

102. Noebels J. A perfect storm: converging paths of epilepsy and Alzheimer's dementia intersect in the hippocampal formation. Epilepsia. (2011) 52(Suppl. 1):39-46. doi: 10.1111/j.1528-1167.2010.02909.x

103. Ren SQ, Yao W, Yan JZ, Jin C, Yin JJ, Yuan J, et al. Amyloid $\beta$ causes excitation/inhibition imbalance through dopamine receptor 1-dependent disruption of fast-spiking GABAergic input in anterior cingulate cortex. Sci Rep. (2018) 8:302. doi: 10.1038/s41598-017-18729-5

104. Heneka MT, Carson MJ, El Khoury J, Landreth GE, Brosseron F, Feinstein DL, et al. Neuroinflammation in Alzheimer's disease. Lancet Neurol. (2015) 14:388-405. doi: 10.1016/S1474-4422(15)70016-5

105. Reams N, Eckner JT, Almeida AA, Aagesen AL, Giordani B, Paulson H, et al. A clinical approach to the diagnosis of traumatic encephalopathy syndrome: a review. JAMA Neurol. (2016) 73:743-9. doi: 10.1001/jamaneurol.2015.5015

106. Loane DJ, Kumar A, Stoica BA, Cabatbat R, Faden AI. Progressive neurodegeneration after experimental brain trauma: association with chronic microglial activation. J Neuropathol Exp Neurol. (2014) 73:1429. doi: 10.1097/NEN.0000000000000021

107. Aungst SL, Kabadi SV, Thompson SM, Stoica BA, Faden AI. Repeated mild traumatic brain injury causes chronic neuroinflammation, changes in hippocampal synaptic plasticity, and associated cognitive deficits. J Cereb Blood Flow Metab. (2014) 34:1223-32. doi: 10.1038/jcbfm.2014.75

108. Pollard H, Khrestchatisky M, Moreau J, Ben-Ari Y, Represa A. Correlation between reactive sprouting and microtubule protein expression in epileptic hippocampus. Neuroscience. (1994) 61:773-87. doi: 10.1016/0306-4522(94)90401-4

109. Zheng P, Shultz SR, Hovens CM, Velakoulis D, Jones NC, O'Brien TJ. Hyperphosphorylated tau is implicated in acquired epilepsy and neuropsychiatric comorbidities. Mol Neurobiol. (2014) 49:1532-9. doi: 10.1007/s12035-013-8601-9

110. Thom M, Liu JY, Thompson P, Phadke R, Narkiewicz M, Martinian L, et al. Neurofibrillary tangle pathology and Braak staging in chronic epilepsy in relation to traumatic brain injury and hippocampal sclerosis: a post-mortem study. Brain. (2011) 134(Pt 10):2969-81. doi: 10.1093/brain/awr209

111. Sen A, Thom M, Martinian L, Harding B, Cross JH, Nikolic M, et al. Pathological tau tangles localize to focal cortical dysplasia in older patients. Epilepsia. (2007) 48:1447-54. doi: 10.1111/j.1528-1167.2007.01107.x

112. Stokin GB, Concepción L, Falzone TL, Brusch RG, Edward R, Mount SL, et al. Axonopathy and transport deficits early in the pathogenesis of Alzheimer's disease. Science. (2005) 307:1282-88. doi: 10.1126/science.1105681

113. van Eersel J, Ke YD, Liu X, Delerue F, Kril JJ, Gotz J, et al. Sodium selenate mitigates tau pathology, neurodegeneration, and functional deficits in Alzheimer's disease models. Proc Natl Acad Sci USA. (2010) 107:1388893. doi: 10.1073/pnas.1009038107

114. Bialer M, Johannessen SI, Levy RH, Perucca E, Tomson T, White HS. Progress report on new antiepileptic drugs: a summary of the Eleventh Eilat Conference (EILAT XI). Epilepsy Res. (2013) 103:230. doi: 10.1016/j.eplepsyres.2012.10.001
115. DeSena AD, Do T, Schulert GS. Systemic autoinflammation with intractable epilepsy managed with interleukin-1 blockade. J Neuroinflammation. (2018) 15:38. doi: 10.1186/s12974-018-1063-2

116. Nowak M, Strzelczyk A, Reif PS, Schorlemmer K, Bauer S, Norwood BA, et al. Minocycline as potent anticonvulsant in a patient with astrocytoma and drug resistant epilepsy. Seizure. (2012) 21:227-8. doi: 10.1016/j.seizure.2011.12.009

117. Iori V, Iyer AM, Ravizza $\mathrm{T}$, Beltrame L, Paracchini L, Marchini S, et al. Blockade of the IL-1R1/TLR4 pathway mediates disease-modification therapeutic effects in a model of acquired epilepsy. Neurobiol Dis. (2017) 99:12-23. doi: 10.1016/j.nbd.2016.12.007

118. Kwon YS, Pineda E, Auvin S, Shin D, Mazarati A, Sankar R. Neuroprotective and antiepileptogenic effects of combination of antiinflammatory drugs in the immature brain. J Neuroinflammation. (2013) 10:30. doi: 10.1186/1742-2094-10-30

119. Bar-Klein G, Cacheaux LP, Kamintsky L, Prager O, Weissberg I, Schoknecht $\mathrm{K}$, et al. Losartan prevents acquired epilepsy via TGF-beta signaling suppression. Ann Neurol. (2014) 75:864-75. doi: 10.1002/ana.24147

120. Putra M, Sharma S, Gage M, Gasser G, Hinojo-Perez A, Olson $\mathrm{A}$, et al. Inducible nitric oxide synthase inhibitor, 1400W, mitigates DFP-induced long-term neurotoxicity in the rat model. Neurobiol Dis. (2020) 133:104443. doi: 10.1016/j.nbd.2019.0 3.031

121. Puttachary S, Sharma S, Verma S, Yang Y, Putra M, Thippeswamy A, et al. 1400W, a highly selective inducible nitric oxide synthase inhibitor is a potential disease modifier in the rat kainate model of temporal lobe epilepsy. Neurobiol Dis. (2016) 93:184-200. doi: 10.1016/j.nbd.2016.05.013

122. Sharma S, Puttachary S, Thippeswamy T. Glial source of nitric oxide in epileptogenesis: a target for disease modification in epilepsy. J Neurosci Res. (2019) 97:1363-77. doi: 10.1002/jnr. 24205

123. Terrone G, Pauletti A, Salamone A, Rizzi M, Villa BR, Porcu L, et al. Inhibition of monoacylglycerol lipase terminates diazepam-resistant status epilepticus in mice and its effects are potentiated by a ketogenic diet. Epilepsia. (2018) 59:79-91. doi: 10.1111/epi.13950

124. Ravizza T, Vezzani A. Pharmacological targeting of brain inflammation in epilepsy: therapeutic perspectives from experimental and clinical studies. Epilepsia Open. (2018) 3(Suppl. 2):133-42. doi: 10.1002/epi4.1 2242

Conflict of Interest: The authors declare that the research was conducted in the absence of any commercial or financial relationships that could be construed as a potential conflict of interest.

Copyright (c) 2021 Sun, Shan, Yang, Liu, Wu and Wang. This is an open-access article distributed under the terms of the Creative Commons Attribution License (CC $B Y)$. The use, distribution or reproduction in other forums is permitted, provided the original author(s) and the copyright owner(s) are credited and that the original publication in this journal is cited, in accordance with accepted academic practice. No use, distribution or reproduction is permitted which does not comply with these terms. 